\title{
Research on Teaching Satisfaction of Graduate Students' Excellent Course
}

\author{
Yangguang $\mathrm{Xu}$ \\ Graduate School of Liaoning University of Science and \\ Technology \\ University of Science and Technology of Liaoning \\ Anshan, China \\ shine216831@sina.com
}

\author{
Xuebo Chen \\ Graduate School of Liaoning University of Science and \\ Technology \\ University of Science and Technology of Liaoning \\ Anshan, China
}

\author{
Qiubai Sun \\ Graduate School of Liaoning University of Science and Technology \\ University of Science and Technology of Liaoning \\ Anshan, China
}

\begin{abstract}
The satisfaction degree of course is the key to measure the success of curricular construction. To improve the quality of postgraduate excellent courses construction in our school, a questionnaire survey against the 6th graduate who took "Linear System Theory And Design," as an elective course. Data was collected via questionnaire investigation, analyzed and verified by based on software package SPSS19.0, the structural equation model and exploratory factor were applied to research the impact factors of the satisfaction of excellent course. We studied the relationship between the degree of participation and satisfaction, with the graduate student participation serving as a latent variable, and got the result of quantitative analysis. On this basis, corresponding countermeasures and suggestions are put forward to improve the quality of excellent course and postgraduates' study as well as the work of administrative department.
\end{abstract}

Keywords-qualified courses; teaching satisfaction; graduate education; questionnaire survey; structural equation model; factor analysis

\section{INTRODUCTION}

Graduate Innovative Education is now a new normal development of higher education development, qualified courses teaching is one of the important means. Top qualified courses is a teaching demonstration programs with top-ranking teacher teams, teaching content, teaching methods, teaching materials as well as teaching management[1]. Curricular construction is an important component of teaching quality of colleges and universities. In recent years, as a result of the organizational leadership and active promotion of ministry of education, construction of quality courses is becoming a hot trend throughout the country, but it is necessary to build a scientific and rational evaluation on it because of the current uneven quality. By the effort and decision-making of our school teaching and research team, we complete the comprehensive and systematic reform of "Linear System Theory and Design" and the construction of excellent course and implement the teaching reform ideas: based on metallurgy, practice-oriented, school-enterprise cooperation, forester students with the broad basic theory and systematic professional knowledge to undertake technical work independently and adapt to the developing advanced engineering technology, our school has formed postgraduate courses with metallurgy-centered and practice-oriented, comprehensive culture of senior technical personnel, teaching at different levels throughout the curriculum, at the same time, we assign modular teaching as the main line, highlight teacherstudent interaction and culture is characterized by comprehensive capacity. Students' evaluation is the most important for the quality of the construction of quality courses, and students' satisfaction with the quality of teaching largely reflects the quality and effectiveness of program construction. To study teaching satisfaction and explore teaching satisfaction factors, we can start the perspective from the students themselves, which can truly reflect the quality of teaching, and thus reflects the quality of the course construction.

At present, most studies have been limited to qualitative analysis and quantitative description of "teaching satisfaction" [2]. R. Carla, G. Leonardo and P. Alessandra think teaching quality is influenced by characteristics of students, their expectation and their interest on the course itself. A.W. Chickering and Z.F. Gamson [3] think that we should improve the quality of teaching from seven parts: teacher-student interaction, collaboration among students, active learning, and timely feedback. Zhang Yueqi, Hu Tiantong and Zhao Liang [4] establish a multiple linear regression models based on CS (Customer Satisfaction) theory, and make qualitative and quantitative analysis of the study of the teaching quality in universities based on the theories and methods for customer satisfaction, and put forward some suggestion for improving the quality of teaching based on the contact point analysis. He Lujun [5] make comparative analysis on the teachers' teaching behavior "importance degree" and students "satisfaction" and draw the conclusions that the two are closely related. Zhang 
Sheqiang, Lu Huawei and Chen Hongtao [6] make a statistical analysis of the satisfaction degree of ideological and political theory teaching and make research and analysis on satisfaction differences and causes of the ideological and political teaching then provide concrete improvements measure.

Factors affecting graduate teaching satisfaction varied, many factors can't be measured directly, it also increases the difficulty to evaluate graduate curriculum, the use of structural equation model and show relationship between measured variable and the latent variable as well as latent variables' relationship in one model.

This template, modified in MS Word 2007 and saved as a "Word 97-2003 Document" for the PC, provides authors with most of the formatting specifications needed for preparing electronic versions of their papers. All standard paper components have been specified for three reasons: (1) ease of use when formatting individual papers, (2) automatic compliance to electronic requirements that facilitate the concurrent or later production of electronic products, and (3) conformity of style throughout conference proceedings. Margins, column widths, line spacing, and type styles are builtin; examples of the type styles are provided throughout this document and are identified in italic type, within parentheses, following the example. Some components, such as multileveled equations, graphics, and tables are not prescribed, although the various table text styles are provided. The formatter will need to create these components, incorporating the applicable criteria that follow.

\section{Methods AND SAMPLING SELECTION}

\section{A. Methods}

Data was obtained by a targeted questionnaire and scale in this study, in which quantitative analysis and empirical research was made and we established a model by using structural equation model. The degrees of satisfaction of graduate education were investigated based on 6th students in my graduate school and factors influencing graduate teaching satisfaction were quantitatively analyzed. For factors influencing teaching satisfaction, 16 measure factors are designed as 16 exogenous observed variables, four latent variables were constructed. For teaching satisfaction survey seven measure factors are designed as observed endogenous variables to explain two endogenous latent variables (named as teaching satisfaction and graduate participation), as shown in Table I, and a full structural equation model is established for relations between latent variables. In this study, data is logged by SPSS 19.0 statistical software, roadmap is designed with structural equation modeling software LISREL8.7, parameter estimation results are obtained by using maximum likelihood estimation, and the calculation results were evaluated by goodness of fit.

TABLE I.

LATENT VARIABLES AND OBSERVED VARIABLES

\begin{tabular}{|c|c|c|c|c|c|}
\hline $\begin{array}{c}\text { latent } \\
\text { variables }\end{array}$ & Symbol & observed variables & latent variables & Symbol & observed variables \\
\hline \multirow{5}{*}{$\begin{array}{l}\text { Teaching } \\
\text { attitude }\end{array}$} & $\mathrm{X}_{1}$ & Serious and responsible preparation & \multirow{4}{*}{ Teaching method } & $\mathrm{X}_{13}$ & $\begin{array}{l}\text { A "seminar" teaching mode, cultivating } \\
\text { students' innovative ability }\end{array}$ \\
\hline & $\mathrm{X}_{2}$ & Be a model for others & & $\mathrm{X}_{14}$ & $\begin{array}{l}\text { Associated engineering practice, training } \\
\text { students to solve practical problems }\end{array}$ \\
\hline & $\mathrm{X}_{3}$ & Teaching seriously, full of enthusiasm & & $\mathrm{X}_{15}$ & $\begin{array}{l}\text { Establish a sound assessment mechanism, } \\
\text { strict control of teaching quality }\end{array}$ \\
\hline & $\mathrm{X}_{4}$ & Rigorous scholarship, strict requirements & & $\mathrm{X}_{16}$ & applications of Information technology \\
\hline & $\mathrm{X}_{5}$ & Friendly exchanges with students & \multirow{4}{*}{$\begin{array}{c}\text { Teaching } \\
\text { satisfaction }\end{array}$} & $\mathrm{Y}_{1}$ & $\begin{array}{l}\text { Whether the content and methods of teaching } \\
\text { are enlightening }\end{array}$ \\
\hline \multirow{3}{*}{$\begin{array}{l}\text { Teaching } \\
\text { Skills }\end{array}$} & $\mathrm{X}_{6}$ & Focus on innovation and practice & & $\mathrm{Y}_{2}$ & Whether teaching methods can be accepted \\
\hline & $\mathrm{X}_{7}$ & Hierarchical teaching & & $\mathrm{Y}_{3}$ & $\begin{array}{l}\text { Whether it helps to develop the ability of } \\
\text { innovation and Practice }\end{array}$ \\
\hline & $\mathrm{X}_{8}$ & Modular teaching, teacher-student interaction & & $\mathrm{Y}_{4}$ & Whether it can stimulate interest in learning \\
\hline \multirow{4}{*}{$\begin{array}{l}\text { Teaching } \\
\text { content }\end{array}$} & $\mathrm{X}_{9}$ & $\begin{array}{l}\text { Course Orientation in graduate training } \\
\text { scheme and Goals of Curriculum }\end{array}$ & \multirow{4}{*}{$\begin{array}{l}\text { Postgraduate } \\
\text { participation }\end{array}$} & $\mathrm{Y}_{5}$ & Interactions with the teacher \\
\hline & $\mathrm{X}_{10}$ & $\begin{array}{l}\text { Sequence and the corresponding hours of } \\
\text { Knowledge modules }\end{array}$ & & $\mathrm{Y}_{6}$ & Discussion among students \\
\hline & $\mathrm{X}_{11}$ & $\begin{array}{l}\text { Key points, difficulties and solutions of the } \\
\text { course. }\end{array}$ & & $\mathrm{Y}_{7}$ & Whether it is helpful for life and learning \\
\hline & $\mathrm{X}_{12}$ & $\begin{array}{l}\text { Design idea and effect of practical teaching } \\
\text { activities }\end{array}$ & & & \\
\hline
\end{tabular}




\section{B. Sampling selection}

To complete a simple and scientific measurement of students and gain accurate and effective figures and statistical results of this study, we choose "Linear System Theory and Design" course in graduate school to students conduct a survey on students. 361 questionnaires were distributed, 361 were recovered, the recovery rate is $100 \%$, and that is to say all the questionnaires are effective.

Likert scale questionnaire [7] is assigned as the way we scoring, with the maximum score being 5 points for each question, the middle value being 3 points, the lowest score being 1 point. Constitution of sample data was shown in Table II.

\section{ESTABLISHMENT AND EVALUATION}

\section{A. Construction of SEM model [8]}

According latent variables and observation index variables of questionnaire, we set up and build the initial model data and obtain structural equation

$$
\left[\begin{array}{l}
\eta_{1} \\
\eta_{2}
\end{array}\right]=\left[\begin{array}{cc}
0 & \beta_{12} \\
0 & 0
\end{array}\right]\left[\begin{array}{l}
\eta_{1} \\
\eta_{2}
\end{array}\right]+\left[\begin{array}{llll}
\gamma_{11} & \gamma_{12} & \gamma_{13} & \gamma_{14} \\
\gamma_{21} & \gamma_{22} & \gamma_{23} & \gamma_{24}
\end{array}\right]\left[\begin{array}{l}
\xi_{1} \\
\xi_{2} \\
\xi_{3} \\
\xi_{4}
\end{array}\right]+\zeta
$$

Where $\eta_{1}$ expresses satisfaction with teaching degrees, $\eta_{2}$ represents student engagement that denotes internal latent variables; $\xi_{i}(i=1,2,3,4)$ indicates latent exogenous variable; $\beta_{12}$ indicates the influence of the endogenous latent variables, $\gamma_{i j}(i=1,2 ; j=1,2,3,4)$ indicates how latent exogenous variables influence endogenous latent variables, $\zeta$ is the internal residual matrix of latent variables.

Exogenous latent variable measurement equation:

$$
X_{i}=\lambda_{i k}^{x} \xi_{k}+e_{i}
$$

Where $X_{i}(i=1,2,3, \ldots, 16)$ denotes external observation variable; $\xi_{1}$ represents teaching attitude, $\xi_{2}$ represents teaching skills, $\xi_{3}$ expresses teaching content representation, $\xi_{4}$ expresses teaching methods that represents external latent variables; $\lambda_{i k}^{x}(k=1,2,3,4)$ is the factor loadings that $\mathrm{i}$-th observation variable on the k-th external latent variables; $e_{i}$ represents measurement errors.

Endogenous latent variable measurement equation:

$$
Y_{j}=\lambda_{j l}^{y} \eta_{l}+d_{j}
$$

Where $Y_{j}(i=1,2,3, \ldots, 7)$ observe internal variable; $\eta_{1}$ represents teaching satisfaction, $\eta_{2}$ represents student engagement that represents internal latent variables; $\lambda_{j l}^{y}(l=1,2)$ is the factor loading that $\mathrm{j}$-th observation of internal variables on the latent variables; $d_{i}(i=1, \cdots, 7)$ represents measurement errors.
We can build models by the software LISREL according to SEM observation equations and structural equation. and then the path coefficients and load factors are normalize by the means of MLE(maximum likelihood estimation), the result are shown in Fig.1.

\section{B. SEM model fit overall evaluation}

$\chi^{2} / \mathrm{df}, \mathrm{RMSEA}, \mathrm{CFI}, \mathrm{NFI}$, IFI and other inspection are selected by this paper as the main parameters to consider the goodness of fit of the model [9]. After the operation of software LISREL, you can get several of goodness of fit index parameter values estimated by SEM model, as is shown in Table III.

\section{Validity of indicators}

Standardized estimated parameters for each latent variable can not only effectively reflect its relevance against the latent variables, but also reflect power that the latent variable explains the index.

From Fig.1, 11 standardized factor loadings on 23 indicators of five latent variables not less than 0.71 , according to the evaluation principles of content validity in structural equation, (the multiple correlation coefficients or factor loadings squared R2 is greater than 0.5 if standardized factor loadings greater than 0.71), which means that the latent variables can explain more than 50 percent problems corresponding to the scale.

TABLE II. SAMPLE DATA CONSTITUTING

\begin{tabular}{|c|c|c|}
\hline Grade & Number of people & Proportion \\
\hline 2008 & 50 & $13.9 \%$ \\
\hline 2009 & 71 & $19.7 \%$ \\
\hline 2011 & 65 & $18.0 \%$ \\
\hline 2012 & 66 & $18.3 \%$ \\
\hline 2013 & 75 & $20.8 \%$ \\
\hline 2014 & 34 & $9.4 \%$ \\
\hline
\end{tabular}

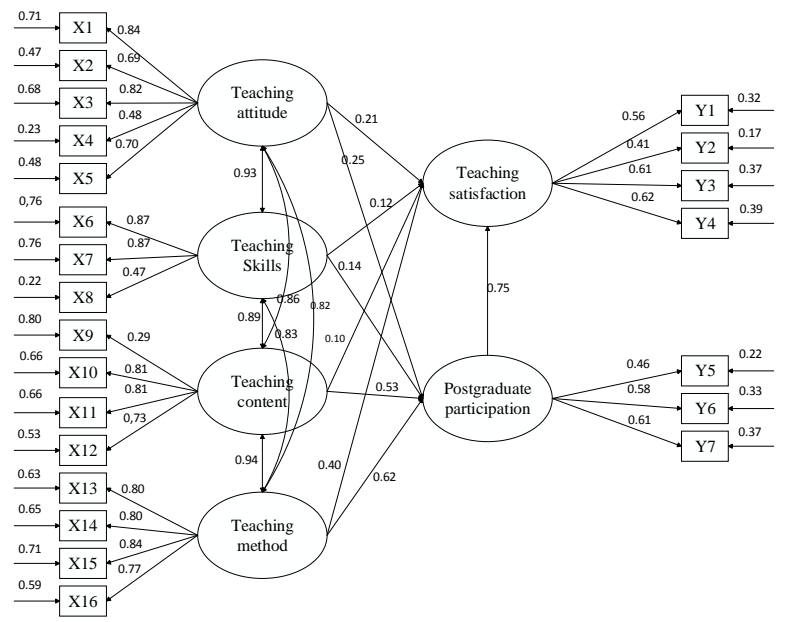

Fig. 1. Standardized SEM roadmap 
TABLE III. FIT INDEX OF MODEL

\begin{tabular}{|l|l|l|l|l|c|}
\hline $\begin{array}{l}\text { Index of goodness } \\
\text { of fit }\end{array}$ & $\chi^{2} / d f$ & RMSEA & CFI & GFI & IFI \\
\hline Estimated value & 1.88 & 0.055 & 0.942 & 0.908 & 0.942 \\
\hline Fitting standard & $\leq 2$ & $\leq 0.08$ & $\geq 0.9$ & $\geq 0.9$ & $\geq 0.9$ \\
\hline
\end{tabular}

\section{Composite reliability of latent variables}

For SEM, the evaluation of the structural model need to test the reliability of potential variables, this test is called composite reliability [10], composite reliability refers to the degree of consistency between latent variable and its corresponding observed variable, and the following statistical indicators are used:

Composite reliability

$$
C R=\frac{\left(\sum \lambda_{i}\right)^{2}}{\left(\sum \lambda_{i}\right)^{2}+\sum\left(\theta_{i}\right)}
$$

CR [11] represents combination of reliability, $\lambda_{i}$ represents normalized factor loading parameters that observed variables against the latent variables, $\theta_{i}$ is the measurement error of observed variables.

Evaluation of CR: 0.90 represents outstanding; 0.80 represents very good; greater than 0.60 indicates acceptable.

As can be seen from Table IV, four in five latent variables' composite reliability reached or greater than 0.80 , far greater than 0.6 (normally required value), indicating that degree of consistency of measured variables and latent variable in this study is still relatively high, thus it can better explain and support its corresponding latent variable.

\section{ANALYSIS OF MODEL}

\section{A. Analysis of the results of measurement equation}

The standardized estimated parameters for each latent variable can not only effectively reflect the relevance between observations and its corresponding latent variables, but also reflect the power that latent variable explain the index.

Judging from Figure 1, two observed variables $X_{1}$ and $X_{3}$ have the greatest impact on teaching attitude $\xi_{1}$, class is the first work of teacher, and preparing lesson plans is a preparatory that work needs to be done before real teaching, therefore, it can be said to adequate effort on lesson plans and serious preparation are the most direct manifestation of the quality of teaching attitudes; another manifestation is teachers' democratic attitude towards every student, because

Listening to students' opinions and suggestions carefully and making improvements timely can suggest that his or her responsibility and serious work and reflect the attitude of teachers from the side.

Two observed variables $\mathrm{X}_{6}$ and $\mathrm{X}_{7}$ have the greatest impact on teaching skills $\xi_{2}$. Practice-oriented lectures, close relation to real life can stimulate interest on learning of students. Structured lectures, clear modules, plain language can help students understand and digest knowledge, and use what they have learned flexibly. We can consider that he or she has good teaching skills once a teacher did that,

Two observation variables $\mathrm{X}_{10}$ and $\mathrm{X}_{11}$ has the greatest impact on teaching content $\xi_{3}$. Teaching content teaching process is the core part of teaching as the longing for knowledge of students at this stage is increasingly more. On the one hand, they hope what they have learned during their college years can link theory with practice, meet the social development and expand their engineering consciousness and ability of engineering practice; on the other hand, they want to be able to acquire more knowledge in a limited time. So this requires synchronism of teaching content and social development, linking theory with practice, and focused.

$\mathrm{X}_{14}$ has the biggest impact on the teaching method $\xi_{4}$, the combination of theory and practice in teaching enable students to understand and apply the knowledge and skills better, so students attach important to teaching method "relating engineering practice, training abilities to solve practical problems".

Observation $\mathrm{Y}_{3}$ has the greatest impact on teaching satisfaction. As the transition from Studies focus on theory at elite education Times into Comprehensive Application Ability now took place, graduates consider cultivation of innovative and practical ability of students. Through combing theoretical knowledge learning and the guidance of instructors, they can integrated into the practice base quickly and better complete hands-on learning [12]. Classroom acceptance rate will naturally increase, as well as the teaching satisfaction.

Observations $\mathrm{Y}_{7}$ has the greatest impact on postgraduate participation. As we all know, applying knowledge we learned to study and live to the greatest extent is the ultimate goal of learning. Students will participate actively and participation rate will increase at well if the course is helpful for learning and life. So whether the courses can help learning and life is a relatively important indicator to explain student engagement.

TABLE IV. COMPOSITE RELIABILITY OF LATENT VARIABLES

\begin{tabular}{|c|c|}
\hline Latent variable & Composite reliability \\
\hline Teaching attitude & 0.83 \\
\hline Teaching skills & 0.74 \\
\hline Teaching content & 0.78 \\
\hline Teaching method & 0.80 \\
\hline Teaching satisfaction & 0.79 \\
\hline Degree of participation among graduates & 0.75 \\
\hline
\end{tabular}

\section{B. Analysis of the results of structural equation}

1) The comparison of impact of teaching attitude $\xi_{1}$, teaching skills $\xi_{2}$, teaching content $\xi_{3}$ and teaching methods $\xi_{4}$ on teaching satisfaction $\eta_{1}$ : the impact from teaching method $\xi_{4}$ is the largest, with its factor loading being 0.40 . Influence from 
teaching attitude $\xi_{1}$ and teaching skills $\xi_{2}$ (absolute value) ranked second; impact from teaching content $\xi_{3}$ is the minimal.

We can see from analysis, influence of the teaching method $\xi_{4}$ on teaching satisfaction $\eta_{1}$ is the biggest. Teaching methods are reflected by four observed variables $X_{13}-X_{16}$, with the loading factor that 4 observed variables on teaching methods being $0.80,0.80,0.84$, and 0.77 . From this, teaching method has a great influence on learning. On the one hand, using the "discussion" teaching mode in the classroom can achieve a teacher-student interaction, active classroom atmosphere and make students involve in classroom teaching and complete the task of teaching in the discussion. We can cultivate self-learning ability and innovation ability of students, give full play to students' learning autonomy and initiative, help and guide students to carry out independent learning effectively. On the other hand, associating content of classroom teaching and practical engineering systems can not only help students understand and learn abstraction and theoretical knowledge of "Linear System Theory and Design" course, but also expand the students' horizons and improve their ability to solve practical issues of engineering. Application of modern information education technology can not only improve teaching efficiency, but can also stimulate student interest in learning and strengthen students' awareness of innovation and practical ability effectively.

The impact from teaching attitude $\xi_{1}$ is Second, with its factor loading being 0.21 .Teaching attitude is reflected by the five observation variables $\mathrm{X}_{1}-\mathrm{X}_{5}$, loading factors of 5 observed variables on teaching attitudes $\xi_{1}$ were $0.83,0.69,0.82,0.48$, 0.70 . From these data we can see, in addition to the fourth one, the loading factors of other four on teaching attitudes $\xi_{1}$ are higher. By this taken, the attitude of teachers has a great influence on students learning attitude, in turn, the attitude of students determines their requirements on teachers' attitudes. On the one hand, if the lesson plans can be prepared carefully and homework can be corrected seriously, good communication and exchange can be made with the students patiently, students tend to have good learning attitude. On the other hand, students in our school have a rigorous climate for learning, so their requirement on themselves in learning is relatively high. They want to gain more knowledge through teaching in order to enrich them, so we have a higher requirement on teaching attitude of their teachers which influence the evaluation on teaching satisfaction of students to a large extent.

Influence from teaching skills and teaching content were $0.12,0.10$. They have lower impacts on teaching satisfaction, but that does not mean teaching skills and teaching content is not important. Excellent courses in our school adopt three modules: teaching module that based mainly on teaching and guiding in order to strengthen precipitation and mastery of important points of theoretical knowledge; research frontier and hot topics module that based mainly on graduate group discussions through case studies in order to strengthen graduates' capacity to expand theoretical knowledge; practical teaching module that based mainly on independent design of postgraduates to strengthen knowledge comprehensive ability and stimulate innovation.

2) The comparison of impact of teaching attitude $\xi_{1}$, teaching skills $\xi_{2}$, teaching content $\xi_{3}$ and teaching methods $\xi_{4}$ on the degree of participation $\eta_{2}$ : the impact from teaching method $\xi_{4}$ and teaching content $\xi_{3}$ are relatively high, while influence from teaching attitude $\xi_{1}$ and teaching skills $\xi_{2}$ (absolute value) are lower.

Effect of teaching content $\xi_{3}$ and teaching methods $\xi_{4}$ is relatively large. Teaching content are reflected by four observed variables $\mathrm{X}_{9}-\mathrm{X}_{12}$, teaching methods are reflected by $\mathrm{X}_{13}-\mathrm{X}_{16}$. Among four observed variables in teaching content, loading factor that $\mathrm{X}_{10}-\mathrm{X}_{12}$ on teaching methods $\xi_{4}$ are as high as $0.81,0.81,0.73$, in which we can see that the students believe synchronization between teaching content and community development, association between theory and practice, a focused, informative teaching that has breadth and depth are the variables that affect the teaching content deeply. Reasons are as following: First, with the development of society, advances in technology, social demand for talent is not just stick to quantity, but also require a qualitative leap. Students broaden their knowledge in order to meet the social demand for talents and lay a good foundation for future employment. So requirements on the depth and breadth of teacher's lectures are increasingly higher. Second, with the increase of students' level of education, they pay more attention to develop their own quality and not limited to the finite knowledge on textbooks. Third, the progress of the times require students to master a wider range of knowledge while it is difficult to complete the work in a limited classroom teaching, which requires teachers to be able to highlight and explain content clearly in the teaching process. For these three reasons, students can actively participate in them because the relatively high guiding role of teaching content on practice and learning.

Loading factor of four observation variables in teaching methods were $0.80,0.80,0.84,0.77$. Through analyzing according to the above results, in the classroom teaching process, emphasis on combination of imparting knowledge and building capacity, theory and practice, inspired and interest cultivated teaching methods can stimulate students' interest in learning, and improve the degree of participation in classroom teaching. The reason is obvious, the teaching methods mentioned above have changed the teaching process of "chalk and talk" approach and make students participate in them actively, so that the entire teaching process has a lively atmosphere and students can learn more knowledge in a relaxed environment at the same time.

\section{STRATEGIES AND SUGGESTIONS}

\section{A. Pay attention to the improvement of teaching level}

Survey results show that college students generally have higher requirements on teaching methods, teaching attitude, teaching skills and teaching contents. Therefore, teachers should deal with these four aspects in the teaching process seriously. 
1) Good teaching attitude of teachers is a basic literacy to teach a course. In the survey results, factor that has a larger impact on teaching satisfaction is teaching attitude. Good teaching attitude (such as preparing lesson plans seriously, correcting work carefully, teaching students patiently, good communication with classmates) can reflect not only coaching literacy, but can affect students' enthusiasm to a large extent.

2) Teaching skill is also an important factor for teaching satisfaction that can't be ignored. In graduate education, the courses of a faculty are mostly taught by experienced teachers. It is very good teaching skills of these experienced teachers, their emphasis on inspired education, interest cultivation, combination of imparting knowledge and building capacity, theory and practice that make teaching effect better.

3) As the core of the classroom teaching, content claims our high attention. Teachers should pay attention to classroom teaching. Teaching content should have the following features: synchronization between teaching content and community development, association between theory and practice, strong emphasis, large sum of information, possession of breadth and depth. So as to meet the students' thirst for knowledge, and to improve teaching satisfaction.

4) As the biggest factor affecting teaching satisfaction, teaching method needs extra attention. We should break the traditional and conventional teaching methods to develop students 'self-learning ability and innovation ability and give full play to students' autonomy and initiative to help and guide students to carry out autonomous learning effectively. In this process, we need respect the dominant position of students in order to increase students' interest in learning and cultivate the students' ability to innovate. The association of classroom teaching content and practical engineering systems not only can help students learn abstraction and theoretical knowledge of "Linear System Theory and Design" course, but also can expand the students' horizons and improve the engineering students' ability to solve practical problems effectively. we can avoid the drawbacks of cramming foe exam occurred in the traditional examination exam in the past and students can get a real quality and the ability, so that students can learn to apply the theoretical knowledge to solve practical engineering system problems and use what they have learned naturally. In this way, a modern engineering education is carried out and students become the talent with abilities

\section{B. Strengthening College Students' self-management}

Some students are getting lazy from college to graduate and even some students go to graduate school just for a diploma, which is related to the administration of management's neglect of student teaching to some extent, but the primary cause is students' insufficient self-management. Therefore, students should continue to improve their overall quality, increase interest in the research and investment and treat classroom teaching rationally from the perspective that their own pay on learning. At the same time, they should strengthen selfmanagement and restraint, understand their own value and what is expected of social, school, family, and view their academic future rationally.

\section{Paying attention to the management of University administration}

Strengthening supervision of the students in university administration also can't be ignored. Once we overlooked this link, it can lead to students' lack of interest in learning, reduced class rate and unenergetic classroom performance and low lectures efficiency, thus affecting the quality of student learning and make evaluation of graduate teaching quality remain a lower level. It is why supervision and management of students can't be ignored.

\section{REFERENCES}

[1] A.W. Chickering and Z.F. Gamson, Seven principles for good practice in undergraduate education [J] .AAHE Bulletin, 1987 (39): 3-7.

[2] R. Carla , G. Leonardo , and P. Alessandra. Analysis of university course evaluations: from descriptive measures to multilevel models [J].Statistical Methods \& Applications, 2004, (13): 357-373.

[3] Li Yinfang. Several issues should be noted in the construction of the course of the University of higher education[J].China high education research, 2007,01:91-93. (In Chinese)

[4] Hu Tiantong, Zhang Yueqi and Zhao Liang. Research on customer satisfaction degree of teaching quality in Colleges and universities [J]. Journal of Tianjin Normal University, 2005 (9). (In Chinese)

[5] He Lujun. The empirical research on the teaching behavior of teacher education "attention degree" and "satisfaction" of students "[J]." Secondary vocational education, 2006 (22). (In Chinese)

[6] Zhang Sheqiang, Wei Hua Lu and Chen Hongtao. College Ideological and political theory course teaching student satisfaction survey and evaluation system construction [J]. Cultural and educational information, 2007(5).(In Chinese)

[7] Wu Qing. Based on the consumption of the scale of the scale of the consumer pension mode survey [J]. Technology and Market, 2013, 20 (8): 188-191. (In Chinese)

[8] Wen Zhonglin, Hou Jietai and Cheng Zijuan. Structural equation model and its application [M]. Beijing: Education Science Press, 2004:25. (In Chinese)

[9] Wen Zhonglin, Hou Jie Tai and Herbert Marsh. Structural equation model to test: fit index and the chi-square criterion [J] Psychology, 2004, 36 (2): 186-194. (In Chinese)

[10] C.L. Shook, D.J. Ketchen, M. Hult and K.M. Kacmar. An assessment of the use of structural equation modeling in strategic management research[J]. Strategic Management Journal, 2004( 25) :397-404.

[11] Xu Wanli. Application of structural equation model in reliability test [J]. Statistics and Information forum, 2008,07:9-13. (In Chinese)

[12] Xu Shaochuan, Jiang Shou Chuan and Chen Xuebo, a graduate student innovation practice base construction path of, Heilongjiang Education: higher education research and evaluation, to 2015 (6): 29-31. (In Chinese) 